\title{
EARLY-AGE CRACK IN CONCRETE IN PEDESTAL STRUCTURES OF SLEEPERS
}

\author{
Dao Van Dinh \\ Dr, Structural Engineering Section -The University of Transport and Communications \\ Add: No.3 Cau Giay Street, Lang Thuong ward, Dong Da District, Hanoi, Vietnam \\ Email: daovandinhkc@utc.edu.vn
}

\begin{abstract}
Cracking in reinforced concrete structures has always been a practical topic discussed by many articles in Vietnam as well as around the world. Many causes could lead to cracking and cracks also can occur at different ages of concrete. Cracking affects the reinforcement corrosion along with the service life of a reinforced concrete structure. Moreover, fractures in concrete influence the appearance of a building, and in some cases provoke the users' feeling of insecurity. Therefore, crack control is often required in many standards for reinforced concrete structures globally. This article presents the sources of cracking at early-age concrete in sleeper pedestal structures of urban railways.
\end{abstract}

Keywords: Early-age crack, concrete, thermal expansion, shrinkage, autogenous shrinkage, External restraint, sleeper, pedestal

Cite this Article: Dao Van Dinh, Early-Age Crack in Concrete in Pedestal Structures of Sleepers, International Journal of Civil Engineering and Technology, 11(6), 2020, pp. 78-88.

https://iaeme.com/Home/issue/IJCIET?Volume $=11 \&$ Issue $=6$

\section{INTRODUCTION}

Cracking in concrete structures has been stated by the EU in EN 1992-1-1 as follows: "Cracking is normal in reinforced concrete structures subjected to bending, shear, torsion or tension resulting from either direct loading or restraint or imposed deformation" [1]. However, in case the crack width is too large, it will have some unfavourable impacts on the structures, such as: 1) Cracks reduce service life and resistance of the structures; 2) Cracks lead to a loss of serviceability of the structures; 3) The appearance of cracks has the negative aesthetic effect or even causes insecure feeling for the users. Consequently, cracking in concrete structures is a matter of the serviceability that all the standard codes in the world require to approach in order to limit crack width.

The sleepers on the pedestal structures of many urban railways are made of reinforced concrete, which play the role of positioning sleepers in three dimensions, instead of balats. The construction of these sleeper structures is carried out as follows: 1) Link prefabricated sleepers to the rails; 2) Position three-dimensional space; 3) Erect reinforced and formwork 
pedestal structures; 4) Set concrete pedestal; 5) Proceed concrete curing; 6) Remove formwork. After removing the formwork, cracks (width around 0.4 to $0.5 \mathrm{~mm}$ ) appear on the pedestal structure at the ends of the sleepers when the age of concrete is less than 7 days, in Figure 1. The task here is to explain the cause of cracks in early age concrete of this pedestal structure's sleeper.

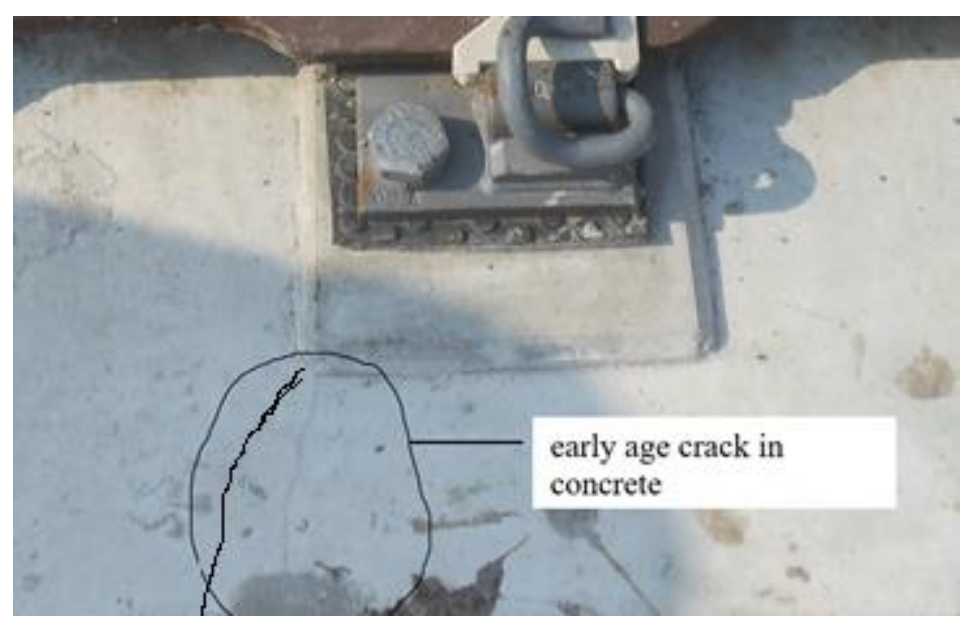

Figure 1 Photo crack at early age in concrete

Figure 2 shows the main dimensions of the sleeper pedestal structure design. The sleeper pedestal structures are made the reinforced concrete.

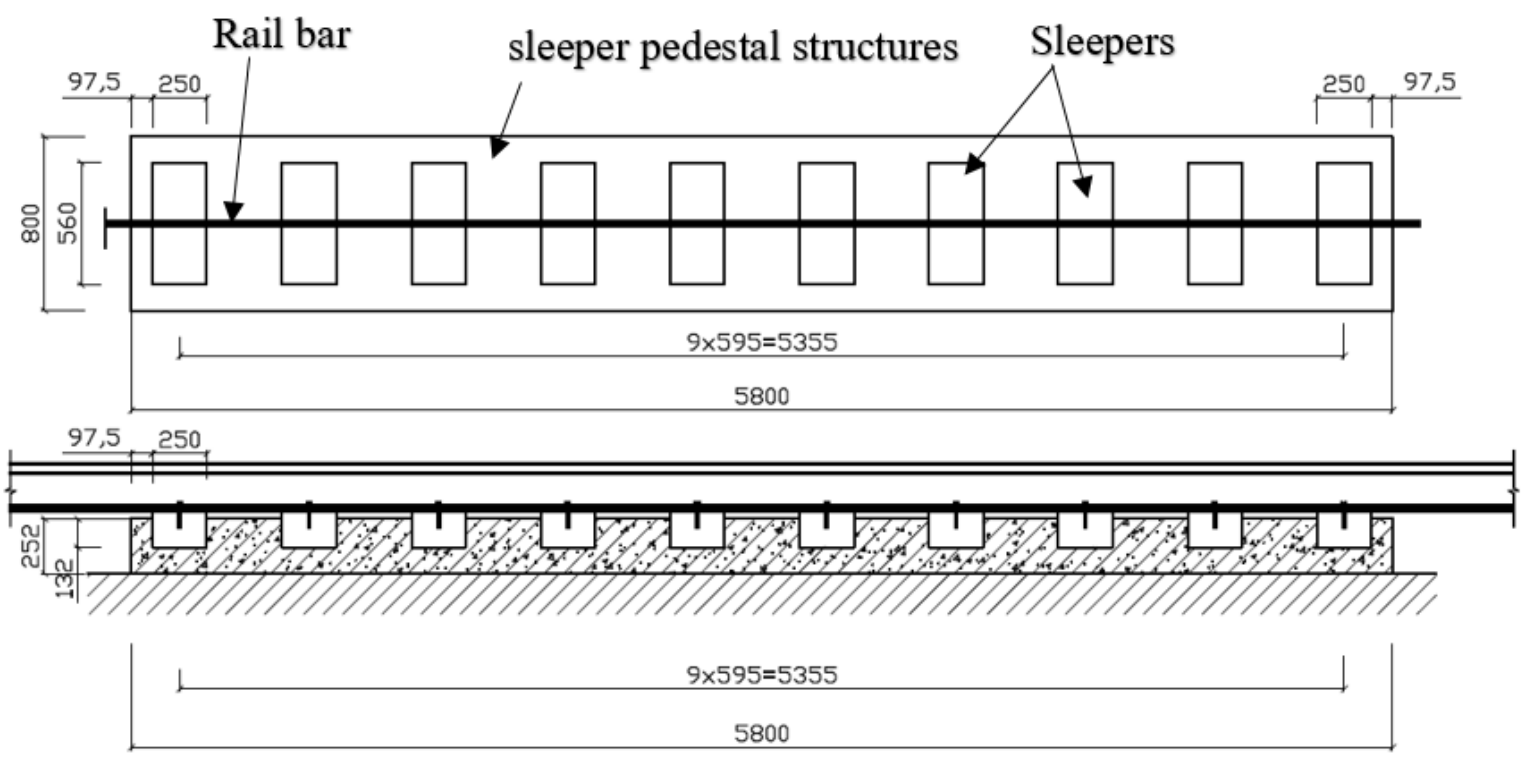

Figure 2 The design of the structure are sleepers

The detail of concrete mix proportion is given in table 1 . The reinforcing steels with the length of $800 \mathrm{~mm}$ are D8, The reinforcing steels with the length of $5800 \mathrm{~mm}$ is D12. The yield strength of reinforced steels are $300 \mathrm{Mpa}$. 
Table 1 Detail of concrete mix proportion

\begin{tabular}{|c|c|c|c|c|c|c|c|}
\hline $\begin{array}{c}\text { Trength class- } \\
\text { cube }\end{array}$ & $\begin{array}{c}\text { Slump } \\
(\mathrm{cm})\end{array}$ & $\begin{array}{c}\text { Cement } \\
(\mathrm{Kg} / \mathrm{m} 3)\end{array}$ & $\begin{array}{c}\text { Water } \\
(\mathrm{kg} / \mathrm{m} 3)\end{array}$ & $\begin{array}{c}\text { Fine } \\
\text { aggregate } \\
(\mathrm{Kg} / \mathrm{m} 3)\end{array}$ & $\begin{array}{c}\text { Coarse } \\
\text { aggregate } \\
(\mathrm{Kg} / \mathrm{m} 3)\end{array}$ & $\begin{array}{c}\text { Additives } \\
(\mathrm{kg} / \mathrm{m} 3)\end{array}$ & $\begin{array}{c}\text { Type of } \\
\text { additive }\end{array}$ \\
\hline $\begin{array}{c}\mathrm{C} 40 \\
(40 \mathrm{MPa})\end{array}$ & $14 \pm 2$ & 449 & 143 & 792 & 1063 & 4.49 & Sky 8588 \\
\hline
\end{tabular}

\section{BACKGOUND OF EARLY AGE CRACKS}

\subsection{Cracking at Early Age Concrete}

The ACI 231 Commission defines "early age" in ACI 231R-10 as "the period after final setting, during which properties are changing rapidly. For a typical Type I portland-cement concrete moist cured at room temperature, this period is approximately 7 days.'[2].

According to CIRIA C660, the aim of researching on cracking at early age concrete is to help both designers and contractors to understand the reasons leading to early-age thermal cracking; to recognise the influencing factors as well as when cracking most likely happens; to evaluate the significance of the cracks; and to come up with avoidance methods and/or control. The factors influencing the early thermal behaviour of concrete are numberous; and consequently there isn't a common rule that identify when cracking will occur. However, these following conditions can increase the risk of cracking: (1) increasing Portland cement content; (2) increasing concrete pouring temperature; (3) increasing concrete pouring thickness; (4) increasing restraint [3].

\subsection{The Cause of Early Age Cracking}

The sources of deformation in early age concrete include: Thermal deformation; Autogenous shrinkage; Drying shrinkage; Creep and stress relaxation from deformation restraint.

The ACI 231-10 wrote [2]: “-The two major driving forces for early-age volume change are the thermal deformation due to cement hydration and shrinkage deformation (autogenous shrinkage and drying shrinkage). The hydration reaction leads to a net reduction in the total volume of the hardened paste, which causes self-desiccation of pores and associated shrinkage."

When the tensile strain in early age concrete is restrained, it will genarete stress. If the tensile stress is greater than the tensile strength of concrete at the corresponding early age, cracks will form.

The general formula for calculating the restrained strain $\varepsilon_{r}$ in early age and long time concrete:

$\varepsilon_{r}=K_{1}\left\{\left[\alpha_{c} T_{1}+\varepsilon_{c a}\right] R_{1}+\alpha_{c} T_{2} R_{2}+\varepsilon_{c d} R_{3}\right\}$

Where:

$T_{1}=T_{p}-T_{a}$

$T_{1}$ is the difference between the peak temperature, $T_{p}$, and the mean ambient temperature $T_{a} ; T_{1}$ is also temperature drop;

$T_{2}$ is the long-term fall in temperature which takes into account the time of year at which the concrete was cast ;

$\alpha_{c}$ is the coefficient of thermal expansion of concrete;

$\varepsilon_{c a}$ is autogenous shrinkage; $\varepsilon_{c d}$ is drying shrinkage;

$R_{1}$ is the restraint factor that applies during the early thermal cycle; 
$R_{2} ; R_{3}$ are restraint factors applying to long-term thermal movement and drying shrinkage respectively;

$K_{1}$ is a coefficient for the effect of stress relaxation due to creep under sustained loading;

Restrained crack-inducing strain in early concrete cracking according to the author of Bamforth, P in CIRIA C660 is:

$\varepsilon_{c r}=\varepsilon_{r}-0,5 \varepsilon_{c t u}$

Where:

$\varepsilon_{c r}$ is crack-inducing strain in concrete defined as the proportion of restrained strain that is relieved when a crack occurs;

$\varepsilon_{c t u}$ is the tensile strain resistane of the concrete under sustained loading;

The verification of the crack condition occurs is:

$\varepsilon_{c r}>\varepsilon_{c t u}$

\subsubsection{Temperature Drop $T_{1}$}

The design process requiring the $T_{1}$ value as an input along with the comprehensive experimental program undertaken by University of Dundee has provided a basis upon which to modify the $T_{1}$ values in order to reflect the behaviour of modern CEM I materials (Dhir et al, 2006). In CIRIA 91 (Harrison, 1992) the values of $T_{1}$ are presented in tabular form for concrete with specific cement contents and for specific components' thickness. In many cases interpolation is required. $T_{1}$ values are shown graphically in Figure 3.
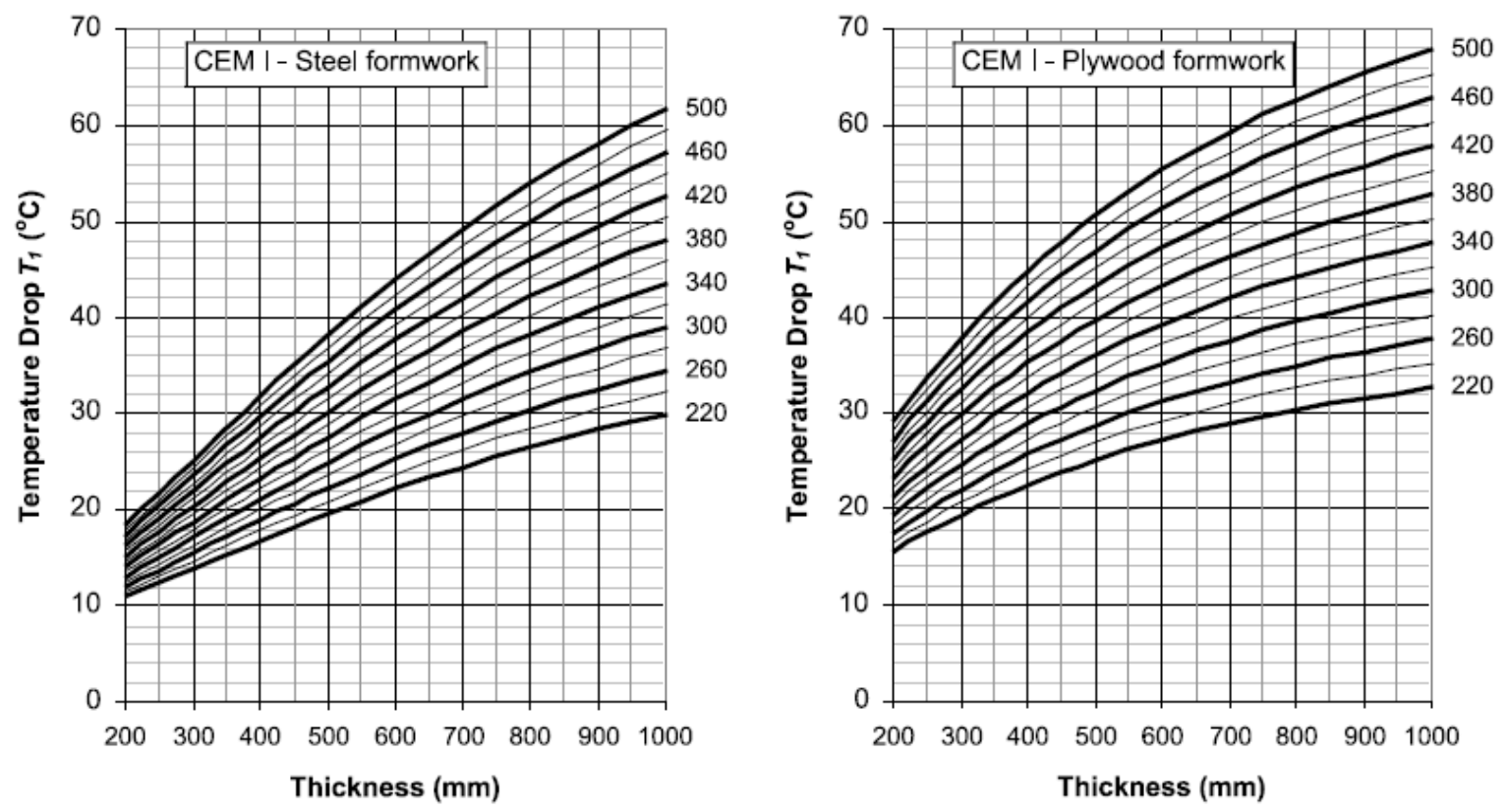

Figure 3 T1 values for CEM I in walls [3]

\subsubsection{Autogenous Shrinkage}

The EN1992-1-1 method for estimating autogeneous shrinkage is only based on the strength classes of concrete and assumes some degree of autogeneous shrinkage occuring in all concrete with a characteristic cylinder strength greater than $10 \mathrm{MPa}$. The ultimate value (in microstrain- $\mu \varepsilon$ ) is given by the expression:

$$
\varepsilon_{c a}(\infty)=2,5\left(f_{c k}-10\right)
$$


The EN1992-1-1 also gives an autogeneous shrinkage strain that occurs at any time calculated by the following formula:

$$
\varepsilon_{c a}(t)=\beta_{a s}(t) \cdot \varepsilon_{c a}(\infty)
$$

Where:

$f_{c k}$ is the characteristic cylinder strength;

$\beta_{a s}(t)$ is a function defining the time dependent development of autogenous shrinkage;

$$
\beta_{a s}(t)=1-\exp \left(-0,2 t^{0,5}\right)
$$

$t$ is the time in days;

\subsubsection{Restraint factor, $R$}

Some criteria that provide guidance on restraint with consideration of various values for the restraint conditions are given in table 2 .

Table 2 External restraint value for different conditions

\begin{tabular}{|c|l|c|c|c|c|c|}
\hline \multicolumn{2}{|c|}{ Restraint condition } & $\begin{array}{c}\text { BS8110 } \\
\text { Part 2 }\end{array}$ & $\begin{array}{c}\text { HA BD } \\
\mathbf{2 8 / 8 7}\end{array}$ & $\begin{array}{c}\text { CIRIA 91 } \\
\mathbf{1 9 9 2}\end{array}$ & BS 8007 & EN 1992-3 \\
\hline A & $\begin{array}{l}\text { Base of a wall cast on to a } \\
\text { massive base }\end{array}$ & $0,6-0,8$ & 0,6 & 1,0 & 0,5 & 0,5 \\
\hline B & $\begin{array}{l}\text { Top of a wall cast on to a } \\
\text { massive base }\end{array}$ & $0,1-0,2$ & & $0,5-1,0$ & $0-0,5$ & $0-0,5$ \\
\hline C & $\begin{array}{l}\text { Edge restraint in box type } \\
\text { deck cast in stages }\end{array}$ & & 0,5 & & & \\
\hline D & Edge element cast onto a slab & & 0,8 & & & \\
\hline E & $\begin{array}{l}\text { Base of massive pour cast } \\
\text { onto existing mass concrete }\end{array}$ & $0,3-0,4$ & & & & \\
\hline F & Suspended slabs & $0,2-0,4$ & & & & \\
\hline G & Infill bays, eg rigid restraint & $0,8-1,0$ & 1,0 & 1,0 & 0,5 & 0,5 \\
\hline
\end{tabular}

\subsubsection{Tensile strain resistant of concrete}

The tensile strain resistance also known as tensile strain capacity $\varepsilon_{c t u}$ is the maximum strain that the concrete can withstand without forming cracks. The tensile strain resistance may be measured directly or derived from the measurements of the tensile strength and the elastic modulus of the concrete. In a comprehensive review of data Tasdemir et al, (1996) developed a simple linear relationship between the $\boldsymbol{\varepsilon}_{\boldsymbol{c t u}}$ and the ratio of the tensile strength $f_{c t m}$ to the elastic modulus $E_{c m}$ as follows [4]:

$$
\varepsilon_{c t u}=1,01 \frac{f_{c t m}}{E_{c m}} \times 10^{6}+8,5 \quad(\mu \varepsilon)
$$

EN1992-1-1 provided functions of concrete properties with age and limited guidance on the impact of aggregate types. These functions are used to produce 3-day and 28-day-old concrete values of $\varepsilon_{c t u}$ given in Figure 4 . 

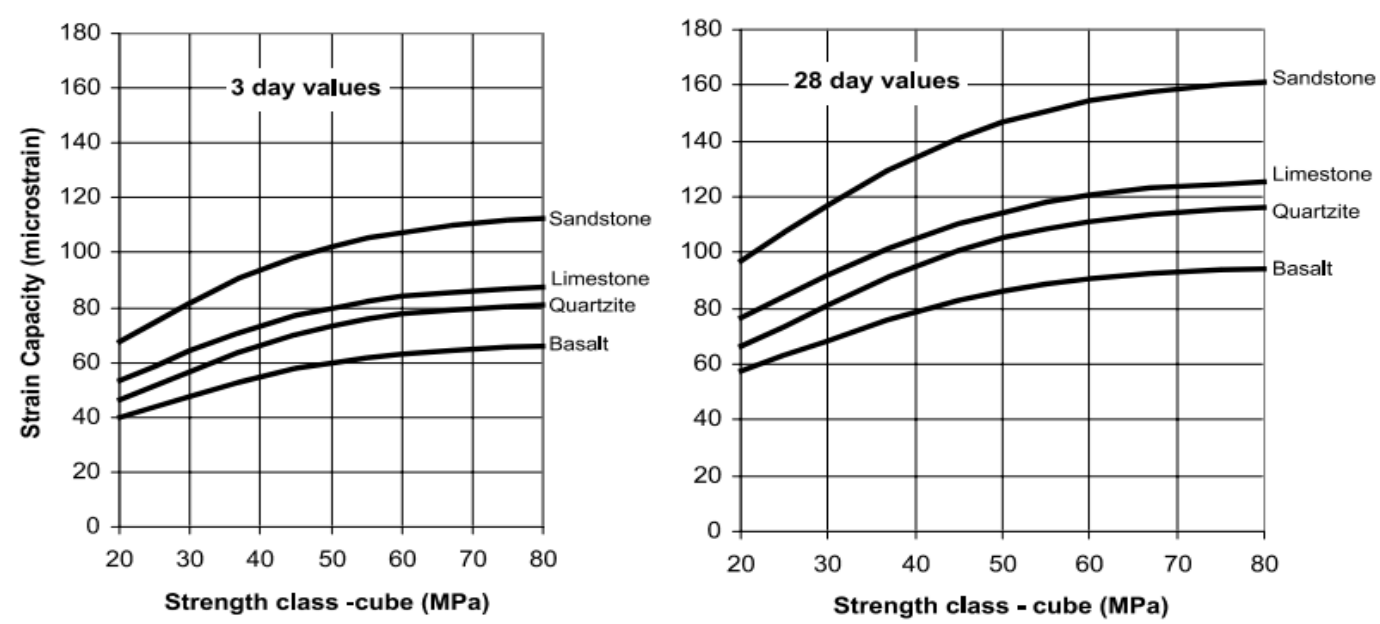

Figure 4 Values of tensile strain capacity at three and 28 days derived using concrete property estimates from EN1992-1-1

\subsubsection{Minimum Area of Reinforcing Steel}

To ensure that crack occur is under control, the area of reinforcement provided must be greater than the minimum steel area. EN1992-1-1 defines the minimum area of reinforcement $A_{s, \min }$ according to the expression [5]:

$$
A_{s, \min }=k_{c} \cdot k \cdot A_{c t} \frac{f_{c t, e f f}}{f_{k y}}
$$

Where: $k_{c}$ is is a coefficient which takes account of the stress distribution within the section immediately prior to cracking $\left(k_{c}=1,0\right.$ for external restraint dominant; $k_{c}=0,50$ for internal restraint dominant, [3]);

$k$ is the coefficient which allows for the effect of non-uniform self-equilibrating stresses, which lead to a reduction of restraint forces. When external restraint bominant: $(\mathrm{k}=1.0$ when $\mathrm{h}<300 \mathrm{~mm} ; \mathrm{k}=0.75 \mathrm{when} \mathrm{h}>800 \mathrm{~mm}$; intermediate values are interpolated); When internal restraint dominant: $\mathrm{k}=1.0 ;[3]$;

$A_{c t}$ is the area of concrete within the tensile zone. The tensile zone is a part of the section which is calculated to be in tension just before formation of the first crack;

$f_{c t, e f f}(t)$ is the mean value of the tensile strength of the concrete effective at the time when the cracks may first be expected to occur: $f_{c t, e f f}=f_{c t m}(t)$ or lower, $\left(f_{c t m}(t)\right)$, if cracking is expected earlier than 28 days; $f_{k y}$ is the yield strength of steel;

\subsubsection{Crack Spacing}

EN 1992-1-1 gives the formula for the maximum crack spacing, $S_{r, \max }$ :

$$
S_{r, m a x}=3,4 c+0,425 \frac{k_{1} k_{2} \phi}{\rho_{p, \text { eff }}}
$$

$c$ is the cover to the reinforcement;

$k_{1}$ is a coefficient which takes account of the bond properties of the reinforcement, $k_{1}=0,8$ for high bond bars; In this case, concrete is early age, so it is recommended that $k_{1}=1,14$; $k_{2}$ is a coefficient which takes account of the distribution of strain, $k_{2}=1,0$;

$\emptyset$ is the bar diameter; 
$\rho_{p, e f f}$ is the ratio of the area of reinforcement to the effective area of concrete $\left(\rho_{p, e f f}=\right.$ $\left.A_{s} / A_{c, \text { eff }}\right)$;

$A_{c, e f f}$ is the effective area of concrete in tension around the reinforcement to a depth of $h_{c, e f}$, where $h_{c, e f}$ is the lesser of $h / 2$ or $2,5(c+\emptyset / 2)$;

\subsubsection{Calculation of Crack Widths}

Regarding the calculation of crack width, EN1992-3 considers two specific conditions: 1) A long wall restrained along one edge; 2)_A tructure restrained at its ends, [6].

a. A member restrained along one edge, $w_{k}$, is calculated by the expression:

$$
\mathrm{W}_{k}=S_{r, m a x} \varepsilon_{c r}
$$

$\varepsilon_{c r}$ is the crack-inducing strain

b. A member restrained at the ends only

For a member subjected to end restraint only, the crack width, wk, is calculated using the expression:

$$
\mathrm{w}_{k}=\frac{0,5 \alpha_{e} k_{c} k f_{c t m}(t)}{E_{s}}\left(1+\frac{1}{\alpha_{e} \rho}\right) S_{r, \max }
$$

$E_{S}$ is the modulus of elasticity of the reinforcement;

$\alpha_{e}$ is the modular ratio $\left(\alpha_{e}=E_{s} / E_{c}(t)\right)$;

$\rho$ is the ratio $A_{s} / A_{c t}$ (Note: $\rho$ differs from $\rho_{p, e f f}$ which is used to calculate the crack width for the edge-restrained condition);

$A_{s}$ is the (total) area of reinforcement;ch của cốt thép;

$A_{c t}$ is the gross section in tension;

\section{THE CRACKING IN EARLY AGE CONCRETE OF SLEEPER PEDESTAL STRUCTURE}

\subsection{The Cracking due to Restraint of a Member at its Ends}

Two cases of end restraint are: the end restraint in the train running direction ( longitudinal side's direction-5800mm side) and the end restraint in the direction perpendicular to the train running direction (direction of transverse side- $800 \mathrm{~mm}$ side).

\subsubsection{End restraint in Longitudinal Direction (5800 $\mathrm{mm}$ side)}

The construction of these sleeper pedestal structures is carried out as follows: 1) Link prefabricated sleepers to the rails; 2) Position three-dimensional space; 3) Erect reinforced and formwork pedestal structures; 4) Set concrete pedestal; 5) Proceed concrete curing; 6) Remove formwork. Because the rails have hard connection to the sleeper, it prevents the shrinkage of pedestal concrete in longitudinal direction, or this is a form of end restraint, Figure 5.

The pedestal structures of sleepers in the train running direction (longitudinal side's direction-5800mm side) can be considered as $800 \mathrm{~mm}$ wide and $5800 \mathrm{~mm}$ long.

General specifications: Concrete pedestal: C37 / 30; Dimensions of pedestal structures: L $=5800 \mathrm{~mm} ; \mathrm{b}=800 \mathrm{~mm} ; \mathrm{h}=252 \mathrm{~mm}$; Reinforcement: transverse bars D12; longitudinal bars D8; concrete cover: 25mm; Sleepers: concrete C50; 560mm long; 250mm wide; steel formwork; Air temperature when pouring concrete pedestal $29^{\circ} \mathrm{C}$; The highest temperature in 3 days of age: $34^{\circ} \mathrm{C}$. 


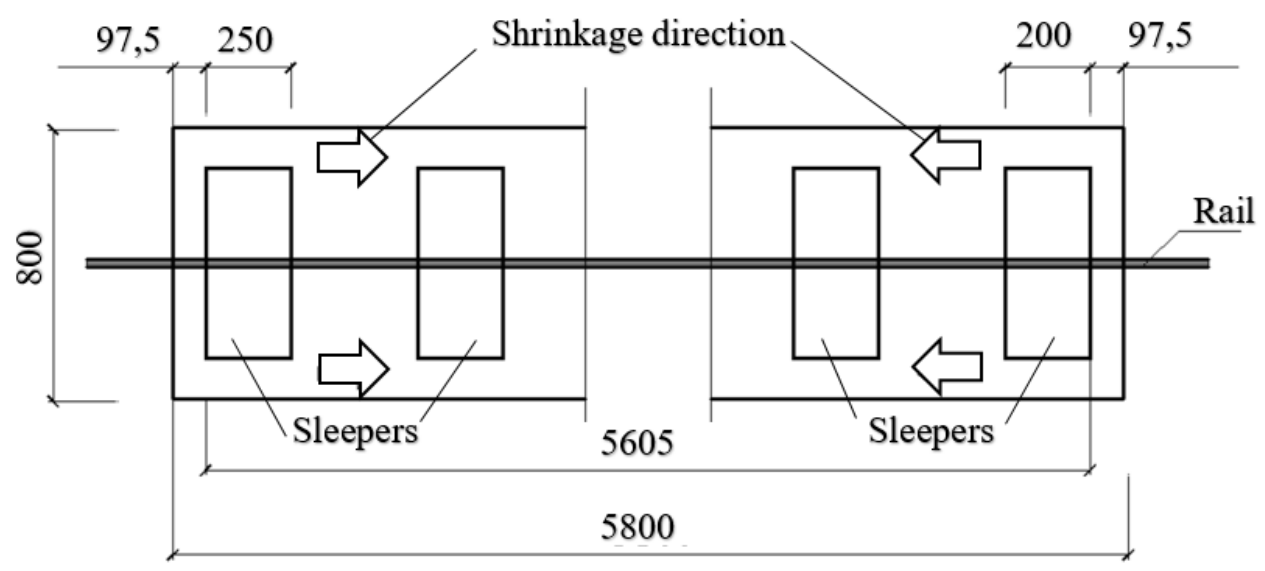

Figure 5 Diagram of early crack due to end restraint in longitudinal direction

For the condition of end restraint, while the magnitude of restrained strain will determine whether or not cracking occurs, the crack width is determined by the tensile strength of the concrete immediately prior to cracking and the resulting stress transferred to the reinforcement. The result calculated for the end restraint in longitudinal direction are presented in Table 3. The crack width calculated is $w=0,39 \mathrm{~mm}$.

Table 3 The outcomes of the end restraint calculations in longitudinal direction

\begin{tabular}{|c|c|}
\hline Parameter & Value \\
\hline$T_{1}$ (độ C) & 36 \\
\hline$\alpha_{c}$ & $10,8 \times 10^{-6}$ \\
\hline$\varepsilon_{c a}(\mu \varepsilon)$ & 15 \\
\hline$R_{1}$ & 0,80 \\
\hline$K_{1}$ & 0,65 \\
\hline$\varepsilon_{r}(\mu \varepsilon)$ & 210 \\
\hline$\varepsilon_{c t u}(\mu \varepsilon)$ & 69,14 \\
\hline$\varepsilon_{r}-0,5 \varepsilon_{c t u}(\mu \varepsilon)$ & 175,21 \\
\hline$f_{c t m} a t 3 d a y s(M P a)$ & 1,73 \\
\hline$A_{c t}\left(m^{2}\right)$ & 100800 \\
\hline$A_{s, \min }\left(\mathrm{mm}^{2}\right)$ & 435,96 \\
\hline$A_{s}\left(\mathrm{~mm}^{2}\right)$ & 565,49 \\
\hline$A_{c, e f f}\left(\mathrm{~mm}^{2}\right)$ & 58000 \\
\hline$S_{r, \max }\left(\mathrm{mm}^{2}\right)$ & 482,55 \\
\hline$w_{k}\left(\mathrm{~mm}^{2}\right)$ & 0,39 \\
\hline
\end{tabular}

\subsubsection{End Restraint in Transverse Direction ( $800 \mathrm{~mm}$ side)}

Reinforced concrete sleepers prevent the concrete pedestal from shrinking horizontally, which is a form of head restraint. The model is calculated as in Figure 6.

Table 4 demonstrates the calculation results for the end restraint in transverse direction. The crack width calculated is $w=0,24 \mathrm{~mm}$. 


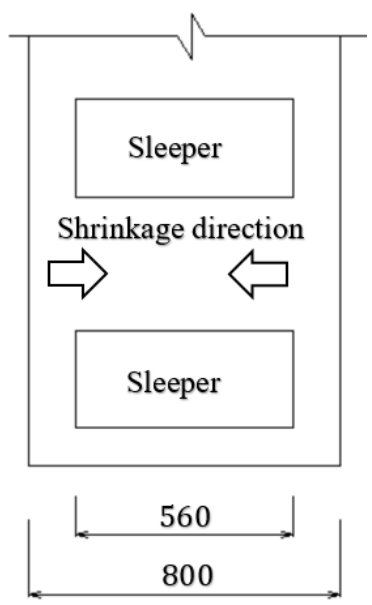

Figure 6 Diagram of early crack due to end restraint in transverse direction

Table 4 The outcomes of the end restraint in transverse direction

\begin{tabular}{|c|c|}
\hline Parameter & Value \\
\hline$T_{1}$ (độ C) & 36 \\
\hline$\alpha_{c}$ & $10,8 \times 10^{-6}$ \\
\hline$\varepsilon_{c a}(\mu \varepsilon)$ & 15 \\
\hline$R_{1}$ & 0,80 \\
\hline$K_{1}$ & 0,65 \\
\hline$\varepsilon_{r}(\mu \varepsilon)$ & 210 \\
\hline$\varepsilon_{c t u}(\mu \varepsilon)$ & 69,14 \\
\hline$\varepsilon_{r}-0,5 \varepsilon_{c t u}(\mu \varepsilon)$ & 175,21 \\
\hline$f_{c t m} a t 3 d a y s(M P a)$ & 1,73 \\
\hline$A_{c t}\left(m m^{2}\right)$ & 74970 \\
\hline$A_{s, \min }\left(\mathrm{mm}^{2}\right)$ & 435,96 \\
\hline$A_{s}\left(\mathrm{~mm}^{2}\right)$ & 550,8 \\
\hline$A_{c, e f f}\left(\mathrm{~mm}^{2}\right)$ & 43137 \\
\hline$S_{r, \max }\left(\mathrm{mm}^{2}\right)$ & 388,56 \\
\hline$\varepsilon_{c r}(\mu \varepsilon)$ & 618,7 \\
\hline$w_{k}(\mathrm{~mm})$ & 0,24 \\
\hline
\end{tabular}

\subsubsection{Direction of the Combination of Two Types of Cracks}

The direction of the combination of two types of cracks is shown figure 7 .

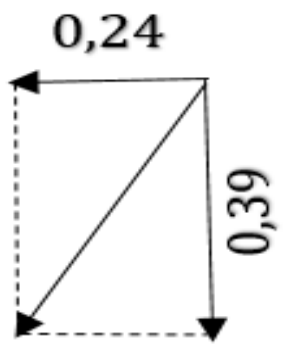

Figure 7 Direction of the combination of two types of cracks 


\subsection{The Cracking due to Restraint of a member at Continuous Edge}

New concrete for the pedestal structures is poured on the concrete deck of the bridge which has been constructed before, so it can be considered that the pedestal concrete is a wall on the old concrete foundation. Model of the edge restraint for the pedestal concrete structure is shown in Figure 8.

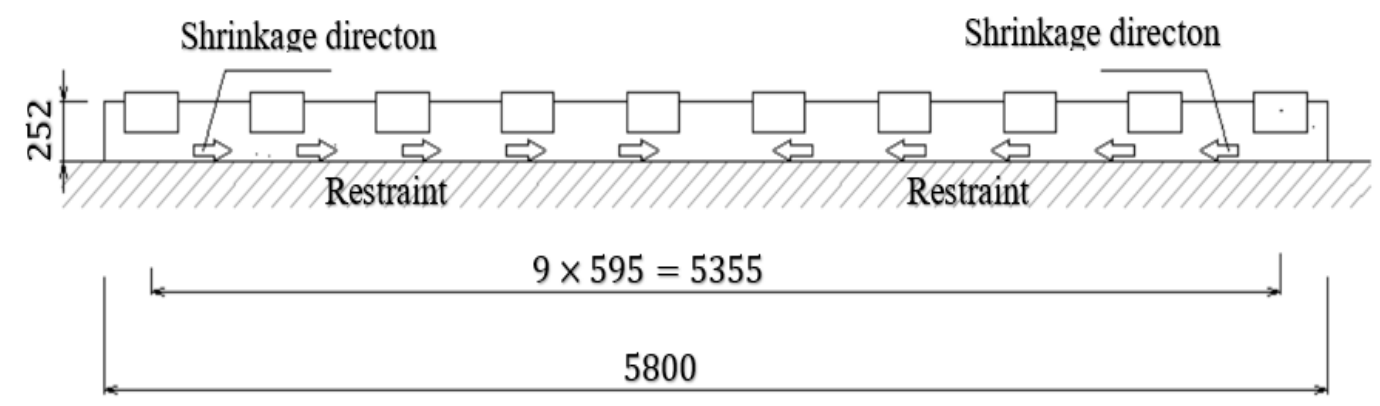

Figure 8 Model continuous edge restraint of the pedestal concrete structure

The results of continuous edge restraint calculations is shown in Table 5. The crack width calculated is $w=0,05 \mathrm{~mm}$.

Table 5 The outcomes of continuous edge restraint calculations

\begin{tabular}{|c|c|}
\hline Parameter & Value \\
\hline$T_{1}($ độ $\mathrm{C})$ & 36 \\
\hline$\alpha_{c}$ & $10,8 \times 10^{-6}$ \\
\hline$\varepsilon_{c a}(\mu \varepsilon)$ & 15 \\
\hline Restraint at the joint $R_{1}$ & 0,51 \\
\hline$K_{1}$ & 0,65 \\
\hline$\varepsilon_{r}(\mu \varepsilon)$ & 135,9 \\
\hline$\varepsilon_{c t u}(\mu \varepsilon)$ & 69,14 \\
\hline$\varepsilon_{r}-0,5 \varepsilon_{c t u}(\mu \varepsilon)$ & 100,52 \\
\hline$f_{c t m} a t 3 d a y s(M P a)$ & 1,73 \\
\hline$A_{c t}\left(m^{2}\right)$ & 100800 \\
\hline$A_{s, \min }\left(\mathrm{mm}^{2}\right)$ & 435,96 \\
\hline$A_{s}\left(\mathrm{~mm}^{2}\right)$ & 791,68 \\
\hline$A_{c, e f f}\left(\mathrm{~mm}^{2}\right)$ & 62000 \\
\hline$S_{r, \max }\left(\mathrm{mm}^{2}\right)$ & 540 \\
\hline$w_{k}\left(\mathrm{~mm}^{2}\right)$ & 0,05 \\
\hline
\end{tabular}

Cracks in early-age concrete due to edge restraint usually derive from the contact of the surfaces between the old and new concrete layers. However, according to the calculation results, the crack width in this particular case is quite small.

\section{CONCLUSION}

Early cracking of reinforced concrete structures is a rather complex problem. The paper presents the early age crack analysis of the concrete pedestal structures at Viet Nam in a simplified way for ease of application.

In order to control the early cracking of reinforced concrete structures, not only the structural design or concrete mix design, the construction work is also certainly critical, for example, the time and the method of curing and the time to remove formwork affect early cracking. 
Among the causes of early cracking in the sleeper pedestal structures above, the head restraint problem can be solved by rubber gaskets or materials that allow high elasticity to seperate sleepers and pedestal structure. Moreover, this gasket allows the sleepers to be easily replaced when they are damaged or out expirary time.

\section{REFERENCES}

[1] EN 1992-1-1-Eurocode 2: Design of concrete structures. 2003, European Committee for Standardization.

[2] ACI231R-10, Report on Early-Age Cracking: Causes, Measurement, and Mitigation. 2010, American Concrete Institute: USA.

[3] Bamforth, P.B., Early-age thermal crack control in concrete. 2007, London: CIRIA C660.

[4] Tasdemir, M.A., Lydon, F D and Barr. B I G, The tensile strain capacity of concrete. Magazine of Concrete Research, Sept 1996. 48, (No. 176): p. 211-218.

[5] Standardization, E.C.f., EN 1992-1-1, in Eurocode 2: Design of concrete structures -Part 1.1: General rules and rules for buildings. 2003.

[6] EN 1992-3:2006-Design of concrete structures - Part 3: Liquid retaining and containment structures. 2006, European Standard. 